Revista lus et Praxis, Año 21, № 1, 2015, pp. $101-136$

ISSN 0717 - 2877

Universidad de Talca - Facultad de Ciencias Jurídicas y Sociales

"La juridificación de las uniones de hecho y la propuesta valórica contenida en el proyecto legislativo de Acuerdo de Vida en Pareja en Chile"

Álvaro Daniel Espinoza Collao

Trabajo recibido el 18 de octubre de 2013 y aprobado el 27 de marzo de 2014

\title{
La juridificación de las uniones de hecho y la propuesta valórica contenida en el proyecto legislativo de Acuerdo de Vida en Pareja en Chile
}

\author{
THE JURIDIFICATION OF DE FACTO UNIONS AND THE PROPOSAL VALUES \\ COntained in the DRAFt legislation Agreement of Life Partner in Chile
}

Álvaro Daniel Espinoza Collao*

\begin{abstract}
RESUMEN
Este trabajo pretende alcanzar un doble objetivo, primeramente, plantea una mirada general a los procesos encaminados a la juridificación de las uniones de hecho en el Derecho comparado, por cuanto las diversas propuestas no resultan estar exentas de conflictos de relevancia jurídica, e implican, al mismo tiempo, un desafío relevante para el legislador para definir el estatuto que resulte más armónico y respetuoso con el interés de los propios convivientes, como con el resto del ordenamiento jurídico.

Este proceso, revitalizado en tiempos modernos como una demanda de sectores marginados de la institución matrimonial, dará paso a su existencia como una forma alternativa para regular la vida en pareja, siendo utilizado cada vez con mayor amplitud en desmedro del matrimonio. Paralelamente, se analizará la situación del reconocimiento jurídico de la convivencia no matrimonial en Chile, ya que este es uno de los últimos ordenamientos que dentro del Derecho occidental no ha regulado de manera específica las uniones de hecho, realidad asumida mayoritariamente en el Derecho de Familia moderno.

En este contexto, se examinará el contenido de carácter ideológico o ético inserto en el proyecto de ley que se encuentra actualmente en tramitación en el Congreso chileno, denominado "Acuerdo de Vida en Pareja", cuya propuesta viene a implementar en el ordenamiento jurídico nacional un estatuto sobre la materia, representando la posibilidad cierta de que por primera vez se regule de manera particular esta realidad social, otorgándoles reconocimiento y protección jurídica.
\end{abstract}

\section{ABSTRACT}

This work aims to achieve a double objective, first of all, presents an overview, processes aimed at the juridification of joints in comparative law, because the various proposals, do not happen to be free of conflicts of legal significance, and mean at the same time, a challenge relevant to the legislator, to define the status that is more harmonious and respectful, with the interest of the own cohabitants, as with the rest of the legal system.

* Profesor de Derecho Civil e Introducción al Derecho, Jornada Completa, Departamento de Ciencias Sociales, Universidad de Tarapacá, Sede Esmeralda, Iquique, Chile. Máster en Derecho de Familia y la Persona (Universidad de Zaragoza, España). Magíster en Educación (Universidad Metropolitana de Ciencias de la Educación, Santiago de Chile). Dirección Postal: Avenida Emilio Recabarren, № 2477, Iquique. Correo electrónico: aespinozac@uta.cl. 
This process, revitalized in modern times, as a demand of marginalized sectors of the institution of marriage, will give way to its existence as an alternative way to regulate the life partner, being used increasingly more broadly to the detriment of the marriage.

At the same time, will analyze the situation of the legal recognition of non-matrimonial cohabitation in Chile, because this is one of the last systems in Western law, has not regulated specifically joints in fact, taken mostly in the modern family law reality.

In this context, will examine the content ideological or ethical insert in the draft law which is currently in the pipeline in the Chilean Congress, called "Agreement of life in couple", whose proposal is to be implemented in the national legal system a statute on the subject, representing the possibility, that for the first time, this social reality is regulated in particular giving them recognition and legal protection.

\section{PALABRAS CLAVE}

Uniones de hecho, Acuerdo de vida en pareja, Derecho de Familia

KeYWORDS

Unions agreement in fact, Life partner, Family law

\section{Acercamiento general a las Uniones de Hecho como fenómeno de interés jurídico}

\subsection{El proceso de juridificación de las uniones de hecho como un desafío ideológico}

Las uniones de hecho no constituyen una realidad uniforme, sino un proceso sujeto a múltiples variables, esta característica se encuentra presente tanto en sus causas como en sus fines. Conceptualmente, la denominación que ha logrado posicionarse de mejor manera en la actualidad es la de "unión de hecho" o "pareja de hecho"1. Este concepto realza el elemento fáctico que caracteriza el fenómeno. Sin embargo, bajo el paradigma actual, este factor se encuentra en entredicho debido a la exhaustiva regulación de la que está siendo objeto, lo que cada vez lo posiciona más cerca del carácter de institución jurídica².

Dentro de las diversas causas asociadas a esta renovada atención por las uniones de hecho, se vinculan los efectos derivados del conjunto de reformas que desde mitad del siglo pasado fueron favoreciendo la situación de la mujer dentro del matrimonio.

\footnotetext{
1 El Parlamento Europeo consultando diferentes fuentes, tanto comunitarias como extracomunitarias, estima que la expresión "parejas de hecho" se ha afianzado más que otras expresiones en español, utilizadas con menor frecuencia para referirse a la misma entidad, como "parejas estables", "parejas (estables) no casadas", "parejas no matrimoniales. Ver: Boletín terminológico y normativo № 48 , de 27.11.2002. Disponible en: http://www.europarl.europa.eu/transl_es/plataforma/pagina/celter/bol48. htm. [visitado el 27/05/2014].

2 A nivel nacional asumen el carácter de institución jurídica: Turner SAelzer (2010), pp. 85-98. También FigueroA YáÑez (2005), pp. 423-446; de la misma manera TAPIA RodríGuez (2007), pp. 155-202.
} 
De este modo, la incorporación de normas igualitarias dentro del régimen matrimonial permitirán que la mujer salga de la esfera de lo privado a lo público, contribuyendo a la economía del hogar, posibilitando su ascenso social y su autonomía económica; cuestión que históricamente estuvo sustentada en una dualidad de autoridad-sumisión frente a la tutela del marido. Estos cambios favorecerán la posición de la mujer, quien demandará, un sistema mucho más respetuoso de su individualidad y autodeterminación ${ }^{3}$.

Frente a estos cambios, la mirada se centró en la crisis de la institución matrimonial, por esencia cuna de familia jurídica; pero entrado el siglo XXI podemos señalar que este proceso responde a un cambio mucho más profundo, asociado a las características estructurales del modelo social, como consecuencia del surgimiento de una sociedad industrializada, globalizada y liberalizada. Así, resulta relevante la incorporación de la mujer a otras esferas de la vida pública, esto contextualizado en un cambio de paradigma que trae consigo una sociedad mucho más democrática.

Estas circunstancias implicarán la necesidad de incorporar en los diversos ordenamientos normativos, la regulación de nuevos modelos de uniones convivenciales de tipo afectivo, en este proceso se confrontarán diversas posiciones ideológicas y valorativas, respecto de la manera en que el Estado debe conformar el orden jurídico familiar.

Gran parte de la discusión respecto de las uniones de hecho se centra en el desafío que representa la búsqueda de la forma más armónica de regular esta realidad social; en la indagación de este equilibrio se deberá tener presente elementos esenciales dentro del Estado de Derecho: el respeto a la igualdad, la libre determinación, pasando por los fines estratégicos asignados a la familia. De la misma manera, se debe confrontar la mirada histórica existente en el Derecho de Familia de raíz occidental, sustentada en el predominio de la figura matrimonial, con la consiguiente inhibición de otras formas de convivencias jurídicamente protegidas.

Las propuestas de regulación estatutarias de las uniones de hecho y su necesidad de legislar sobre la materia, suelen justificarse básicamente en tres tipos de argumentos: a) El dato sociológico, justificado en la demanda de amplios sectores de la población que apoyan la causa; asimismo, en el aumento del número de parejas que conviven y su progresiva aceptación por la sociedad ${ }^{4}$;

${ }^{3}$ Lacruz Berdejo et al. (2005), p. 289.

${ }^{4}$ Así se puede observar a modo de ejemplo: En el Preámbulo de la ley № 5/2003, de regulación de las parejas de hecho, de la Comunidad Autónoma de Canarias; ley № 232 sobre Hogar común de cohabitantes extramatrimoniales de Suecia de 1987; ley № 1004 de la legislatura federal de la ciudad autónoma de Buenos Aires de 2002; ley No 18.246 sobre Unión Concubinaria de Uruguay de 2008; En el proyecto de Ley de Acuerdo de Vida en Pareja, Mensaje No 156/359 del año 2011. 
b) Los requerimientos en relación con conceptos constitucionales. Los principales son: -la demanda de protección a la familia existente en la convivencia estable y duradera ${ }^{5}$-; el respeto al libre desarrollo de la personalidad; -el derecho de igualdad con la prohibición de discriminación (este último se presenta principalmente en la demanda de la población homosexual $\left.{ }^{6}\right)$. En este mismo sentido, se alude también al derecho a no contraer matrimonio, y a optar por un modelo familiar distinto ${ }^{7}$; c) Un tercer argumento de fundamentación es la remisión a las orientaciones y resoluciones de organismos internacionales, vinculadas a la protección de los Derechos Humanos ${ }^{8}$.

Debiésemos agregar a lo anterior el factor de preponderancia política, reflejado en los cambios de visión de diversos sectores políticos, que durante largo tiempo defendieron la dualidad de familia-matrimonio, quienes propiciados por los altos índices de personas que conviven fuera del matrimonio debieron favorecer los diversos proyectos legislativos enfrentados a la lógica electoral ${ }^{9}$.

La discusión central se orientará a la forma como asumir este cambio en la estructura normativa. Para Martínez de Aguirre, la respuesta pasa por reconocer la idea de diversidad jurídica, tanto desde un punto de vista estructural como funcional, focalizado en el planteamiento de las funciones estratégicas que se asigna a cada grupo, características que no son traspasables a entidades de naturaleza diferente.

Desde esta mirada, no todos los grupos plantean un desafío de interés para el Derecho, debido a su eficacia para cumplir las funciones estratégicas asignadas por el Estado a la familia. Se propone el establecimiento de estatutos diferenciados ajustados a las características propias de cada entidad. Así, se busca una adecuación a los cambios que enfrenta la sociedad moderna, sustituyendo el cauce único para su regulación, asimilado regularmente a la institución ma-

5 Sobre esta materia: Roca Trias (2006), pp. 207-228. De la misma manera SÁnchez MARTínez (2000), pp. 45-69.

${ }^{6}$ Así se observa, entre otros, en: Exposición de Motivos de la ley № 5/2003, de parejas de hecho, de la Comunidad Autónoma de Extremadura; Exposición de Motivos de la ley foral № 6/2000, para la igualdad jurídica de las parejas estables, de la Comunidad Autónoma de Navarra; en el proyecto de Ley de Acuerdo de Vida en Pareja, Mensaje № 156/359 del año 2011.

7 Exposición de Motivos de la ley foral No 6/2000, para la igualdad jurídica de las parejas estables, de la Comunidad Autónoma de Navarra; Exposición de Motivos de la ley № 2/2003, reguladora de las parejas de hecho, del Parlamento Vasco.

${ }^{8}$ En el caso de la comunidad europea se encuentran por ejemplo las Resoluciones del Parlamento Europeo tales como: la resolución del 16/3/2000 sobre equiparación entre familia y uniones de hecho; la resolución del 8 de febrero de 1994, sobre la igualdad de derechos para los homosexuales entre otras.

${ }^{9}$ Gavidia Sánchez (2004), p. 2. Señala, a propósito de institucionalizar las uniones de hecho, que en un Estado democrático, el cálculo electoral, los compromisos con poderes fácticos, lleven a unos y otros a propiciar o no esa institucionalización". 
trimonial, estableciendo sus propios estatutos a los que cada individuo podrá optar libremente ${ }^{10}$.

De esta manera, podemos justificar bajo esta premisa el concepto de un régimen matrimonial altamente protegido, de carácter heterosexual y con acceso restringido a su disolubilidad; y paralelamente, otros regímenes más o menos disolubles, al que pueden tener acceso parejas tanto del mismo como de diferentes sexos, esto dependiendo de la eficacia que representen estas convivencias para cumplir las funciones estratégicas que se asignan a la familia dentro del orden social ${ }^{11}$.

El gran inconveniente de esta propuesta es que solo resulta posible en la medida que con ello no se establezcan regímenes de primer y segundo grado, justificando un trato preferencial ajustado a la funcionalidad que represente para los fines de la colectividad. De este modo, postulamos que ello implicaría una vulneración a ciertas garantías individuales como el derecho a un trato igualitario y libre de toda discriminación; además de instrumentalizar a los individuos frente a los objetivos que tiene el Estado ${ }^{12}$.

En un camino completamente distinto se fundamenta la necesidad de remover obstáculos e impedimentos para la regularización de otras formas de convivencias por parte de los poderes públicos, para que quienes opten por estas formas lo puedan realizar en un plano de libertad e igualdad. En ello se manifiesta negativamente la garantía del "Ius Conubii", como el derecho a no contraer matrimonio, como respeto al libre desarrollo de la personalidad y a la no discriminación por estado civil de las personas que deseen conservar el derecho a estar soltero, logrando cautelar la libertad de elección entre el matrimonio y otros modelos.

Bajo esta mirada podemos reconocer a las uniones de hecho como fuente posible de relaciones jurídicas de tipo familiar, siempre que se configuren determinadas características tales como: comunidad de vida, cuidados personales y responsabilidades recíprocas, que no se sustenten únicamente en la mera convivencia, sino bajo rangos de exclusividad, estabilidad y duración, elementos

\footnotetext{
10 Martínez De Aguirre Aldaz (2007), pp. 742-744. Se propone el modelo de matrimonio existente en Estados Unidos, Ilamado "Matrimonio-Alianza" (covenant marriage), en el que los cónyuges asumen esforzarse por resolver sus posibles diferencias sin recurrir al divorcio, además se limitan fuertemente las causas legales de divorcio.

11 GuZmán Brito (2001), pp. 283-285. En la misma línea, postula que el conflicto respecto al establecimiento del divorcio se resolvía estableciendo regímenes matrimoniales diferenciados, uno con divorcio y otro sin divorcio, ya que el establecimiento de un estatuto siempre vulneraba la libertad de parte de la comunidad.

12 Parte de la doctrina justifica un tratamiento diferenciado respecto de la atención y protección que debe prestar el Estado, justifican esta diferencia en el origen diverso en que se sustentan. En este sentido: Barrientos Grandon (2011), p. 34.
} 
propios de la estructura familiar; reservándose como característica particular la libre disolubilidad del vínculo.

Por cierto, esta progresiva legalización de los modelos extramatrimoniales, unida a la actual reivindicación de igual trato jurídico, ha generado estatutos poco diferenciados, con figuras e instituciones de contenido y límites difusos, cuestionándose la vulneración de la libertad de las personas de mantenerse al margen de todo régimen ${ }^{13}$.

Desde esta perspectiva, actualmente nuestra sociedad no conoce un único modelo familiar, sino una multiplicidad de estructuras que resultan de las diferentes concepciones existentes sobre la sexualidad y las relaciones afectivas. Mediante estas alternativas, las parejas en ejercicio de su libertad pueden optar para organizar sus relaciones, dentro de unos límites crecientemente amplios, de forma que al Derecho sólo le quedaría reconocer y regular estas situaciones.

La tendencia actual implica la materialización de un cambio de visión de sociedades altamente influenciadas por tendencias conservadoras. Este paradigma revitalizado por la demanda de sectores marginados del matrimonio dará paso a una forma alternativa de regular la vida en pareja, utilizado cada vez más en desmedro del matrimonio ${ }^{14}$.

\subsection{Una mirada al Derecho comparado}

Las uniones de hecho tienen una larga data histórica de atención por parte del Derecho, la respuesta que se ha otorgado a los problemas que plantea su existencia ha variado a lo largo de la historia, extendiéndose desde la indiferencia absoluta, acompañada de un trato negativo, que dominó hasta finales del siglo XX; pasando por su equiparación total a la figura matrimonial, como en el caso de Holanda y Bélgica, hasta el establecimiento de un estatuto general, destinado a regular de manera específica el fenómeno, como es el caso del Pacto de Solidaridad Francés (PAC).

No obstante, los antecedentes primarios nos remontan al Derecho romano clásico, en que surge por primera vez la denominación concubinato para referirse a las relaciones ilegítimas entre varón y mujer. Este tipo de relaciones no estaba expresamente regulado, pero estaba permitido como una forma de convivencia distinta al matrimonio ${ }^{15}$. Esta definición de "concubinato" para referirse a este tipo de convivencias no matrimoniales ha comenzado a ser abandonada como

\footnotetext{
13 Sobre la materia ver: Talavera Fernández (2001). En un sentido crítico sobre la misma materia ver: García Cantero (2004), p. 13.

14 Sobre la materia ver: Del Picó Rubio (2011), pp. 31-56. En el mismo sentido: Corral TalCiani (2012), p. 10.

15 Parra Martín (2005), p. 243.
} 
referencia, sin embargo, continúa siendo utilizada tanto en la legislación como también a nivel jurisprudencial ${ }^{16}$. Cabe aclarar que las uniones de hecho actuales tienen muy poco en común con el concubinato romano, por cuanto estas últimas responden a una estructura social concreta, en cambio las primeras son una manifestación de un derecho individual, garantizado mediante el desarrollo de la propia personalidad ${ }^{17}$.

En la realidad Latinoamericana este tipo de uniones encuentran su origen histórico en la costumbre de los pueblos prehispánicos. Durante el imperio incaico surge la figura del "Tantanacu" o "Servinacuy", caracterizado como una unión entre un hombre y una mujer, cuyo propósito es constituirse como un período de prueba para el matrimonio, este tenía una duración de un año, al cabo del cual debía celebrarse el matrimonio.

Se discute respecto a la naturaleza de esta figura, si se trata de una modalidad de matrimonio a prueba, o bien, constituye un matrimonio propiamente tal, al que se accede sin necesidad de formalización por parte del Estado o la iglesia. Estas formas de uniones ancestrales se encuentran tan arraigadas en la población que lograron sobrevivir al transcurso del tiempo, siendo reconocidas jurídicamente en la Constitución Boliviana ${ }^{18}$.

En el Derecho occidental, durante un largo período, las relaciones al margen del matrimonio no representaron interés, incluso este tipo de relaciones fueron castigadas, considerándose ilícitas ${ }^{19}$.

Posteriormente se presentará un interés sólo fragmentario en este primer modelo de regulación de las uniones de hecho, intervienen diversas miradas, desde considerar a las uniones de hecho indignas para el Derecho, por su

${ }^{16}$ El artículo 210 del Código Civil chileno señala: "El concubinato de la madre con el supuesto padre, durante la época en que ha podido producirse legalmente la concepción, servirá de base para una presunción judicial de paternidad". La Ley sobre Abandono de Hogar y Pago de Pensiones Alimenticias ( $N^{\circ}$ 14.908), en su derogado artículo 18, declaraba solidariamente responsable al pago de la pensión alimenticia al concubino del alimentante. A nivel jurisprudencial véase como ejemplo: Corte Suprema de Chile, 7 de marzo del 2012, rol № 337-2011; Corte de Apelaciones de Concepción, 15 de marzo de 2013, rol No 38-2013

17 Cantero Núñez (2001), pp. 280-281.

${ }^{18}$ Ver: El Código de Familia de Bolivia, promulgado el 2 de agosto de 1972, en su artículo 160 bajo el título "Formas Prematrimoniales Indígenas y otras Uniones de Hecho". Sobre esta materia: Cornejo ChÁvez (1999), pp. 74-79.

${ }^{19}$ En Chile el Código Penal de 1875, en su artículo 381 consagró el delito de amancebamiento respecto del marido cuando este tuviere manceba dentro de la casa conyugal, o fuera de ella con escándalo, esto en referencia a relaciones de convivencia con cierta permanencia. Además, se contemplaba el delito de adulterio respecto de la "mujer que yacía con hombre" distinto del marido, con una penalidad más elevada que el delito de amancebamiento. Estos delitos fueron derogados por la ley $\mathrm{N}^{\circ} 19.335$ de septiembre de 1994. Barrientos Grandon (2008), pp. 7-8. 
carácter de unión ilícita, hasta posiciones libertarias que pretenden fundar la bondad de este modelo en el respeto a la libertad individual.

En este período se dictan una serie de leyes aisladas, que solo reconocen efectos limitados atendiendo a los problemas de naturaleza patrimonial, derivados de las adquisiciones durante la convivencia. Mientras en forma paralela la jurisprudencia asumirá su labor de fuente de derecho, para dar solución a los principales conflictos ${ }^{20}$.

Serán los países escandinavos quienes darán inicio a un nuevo proceso de atención jurídica, esto durante los años 80 del siglo pasado, mediante la dictación de leyes cuyo principal objeto será la regulación de los efectos económicos derivados de la convivencia continuada de dos personas. Inicialmente esta regulación tendrá como sujetos únicamente a convivientes homosexuales, luego se extenderá también a convivientes de distinto sexo ${ }^{21}$.

La idea central de estas propuestas, puesto que los contrayentes heterosexuales ya podían casarse, era regular la situación de las parejas homosexuales para que pudieran tener la certeza jurídica que otorga algún régimen legal. Por ello, el foco de estos estatutos es asimilar las uniones de hecho a la estructura del régimen matrimonial.

Cabe precisar que estas propuestas tendientes a resolver conflictos de naturaleza patrimonial se sitúan de manera prioritaria en la división equitativa de los bienes, principalmente la vivienda y enseres domésticos, frente al proceso de ruptura de la pareja. De esta forma, no se ubican dentro del Derecho de Familia, sino en el ámbito exclusivo del Derecho patrimonial, preservando la exclusividad del matrimonio, como única figura institucional reguladora de las relaciones afectivas de pareja ${ }^{22}$.

En esta evolución, la situación de Holanda marca una diferencia en el tratamiento existente a la fecha. El año 1997 el Parlamento holandés aprobó el Proyecto de Ley de Reforma al Código Civil y del Código de Procedimiento Civil, relativo a la inscripción de los convivientes, incorporando al Código Civil un título denominado "La convivencia inscrita".

\footnotetext{
${ }^{20}$ Dentro de las posiciones asumidas por la jurisprudencia, se reitera el reclamo de la idea de la copropiedad y con menos frecuencia la sociedad universal. Destacan la utilización de la línea del principio general del enriquecimiento sin causa, para efectos de evitar los perjuicios a los convivientes frente a la ruptura. Díez-Picazo y Gullón Ballesteros (2012), p. 70.

21 Suecia optó inicialmente por una regulación parcial de las uniones no matrimoniales, con la promulgación de la ley № 232/87, sobre el hogar común de los convivientes de hecho. Será Dinamarca el primer ordenamiento en aprobar, en 1989, una ley que permite a dos personas del mismo sexo inscribir su unión en un registro público. Posteriormente Noruega en 1993, Suecia en 1994, Islandia en 1996 y Finlandia en 2001 siguieron el mismo modelo.

22 En este sentido: Talavera Fernández (2007), p. 7.
} 
A diferencia de los sistemas desarrollados anteriormente, esta propuesta se encuentra abierta no sólo a los homosexuales, sino que admitirá la inscripción de parejas heterosexuales; permitiendo por primera vez el acceso a este tipo de régimen a personas que tenían libre ingreso al matrimonio, estableciéndose como un régimen alternativo, sujeto a elección por parte de los convivientes.

Así, se establecerá una proposición novedosa en la técnica legislativa, ya que esta modalidad se remitirá en bloque al estatuto matrimonial, para la regulación de las uniones de hecho, esto en materias estructurales como la capacidad, derechos y deberes de los convivientes, excepcionando únicamente las relaciones jurídico-familiares, respecto a las obligaciones parentales.

En este contexto, podemos señalar que actualmente las parejas heterosexuales disponen de una amplia diversidad de estatutos para regular su convivencia, estos son: a) matrimonio; b) la unión registrada y c) el pacto de convivencia ${ }^{23}$. Esta multiplicidad de regímenes, si bien inicialmente se presentará como una respuesta integral, actualmente se halla en entredicho, al provocarse un acercamiento de tal magnitud entre cada estatuto que prácticamente se han sobrepuesto; cuestionándose la utilidad de esta coexistencia.

Otra modalidad de regulación está representada por el Pacto Civil de Solidaridad Francés (PAC). La entrada en vigencia del PAC en el año 1999, les permitió a las parejas optar por diversas formas de regulación de su convivencia, estos modos son: a) concubinato, entendiéndose como tal a las convivencias no reguladas de forma alguna, sustentada en el elemento fáctico; b) pacto de convivencia, que es un contrato mediante el cual los convivientes regulan su vida común; y c) el régimen matrimonial. Cabe aclarar, que en el caso de las parejas homosexuales, inicialmente sólo podían optar por las dos primeras figuras, esto hasta el mes de abril del año 2013, en que la Asamblea Nacional francesa aprobó el matrimonio homosexual.

Las principales diferencias del PAC con los otros modelos consisten: a) en su distanciamiento del régimen matrimonial, manteniendo estatutos claramente diferenciados, tanto en su estructura como en el alcance de sus efectos; b) su aplicación se extendió a un catálogo amplio de relaciones de dependencia personal, económica y afectiva, que no requieren necesariamente un sustrato de connotación sexual, entre personas que comparten un cierto proyecto de vida en común ${ }^{24}$.

${ }^{23}$ García Rubio (2006), p. 126.

${ }^{24}$ Como ejemplo de este distanciamiento podemos destacar su régimen de publicidad, ya que estas uniones no se inscriben en el Registro Civil, sino en un registro judicial especial Ilamado "Tribunales de instancia"; tampoco se producen los efectos del matrimonio en el ámbito fiscal ni en el de los derechos sociales y se permite la resolución del pacto sin necesidad de intervención judicial. 
Por su parte, en España no se ha efectuado un tratamiento sistemático a nivel estatal, sin que ello alcance una situación de anomia; por cuanto existe una regulación parcial por parte de la mayoría de las comunidades autónomas, sin que a la fecha se haya logrado un consenso político para un tratamiento integral. La mayoría de las comunidades han optado por dictar leyes específicas para su regulación, existiendo una gran heterogeneidad entre todas ellas, destacándose como elemento común su aplicación integral tanto a parejas del mismo como de diferente sexo.

La primera ley autonómica se dictó en el año 1998, en la comunidad autónoma de Cataluña, la "Ley de Uniones Estables de Pareja" propuso una regulación diferenciada entre parejas heterosexuales y homosexuales. Entre sus principales características se puede señalar: a) los convivientes heterosexuales podían constituirse bajo un régimen de carácter imperativo, bastando la convivencia ininterrumpida durante dos años, o bien, la simple convivencia, si tenían un hijo común; también podían recurrir por su mera voluntad, mediante su declaración por escritura pública. En cambio, las parejas del mismo sexo, sólo podían constituirse mediante manifestación en escritura pública; b) no era necesario inscripción en registro público; c) por cuanto a sus efectos, no existen grandes diferencias entre parejas formalizadas y no formalizadas, se le reconocen los mismos derechos, tanto si se habían constituido por mera convivencia, o mediante documento público ${ }^{25}$.

En Latinoamérica esta realidad ha sido asumida durante los últimos diez años mediante la promulgación de diversas leyes. Será Argentina la pionera en América Latina en reconocer bajo un concepto igualitario derechos y obligaciones de los concubinos de cualquier sexo, con la dictación de la ley número 1004, aprobada por la Legislatura de la Ciudad Autónoma de Buenos Aires, el 12 de diciembre de 2002. Este modelo se asienta en una visión pluralista, incorporando de manera igualitaria a todas las parejas sin distinción de sexo, respondiendo a la idea de promover la igualdad y de no discriminar a las personas en razón de su orientación sexual.

Esta forma de ordenación, asume el concepto de "uniones civiles", esto como distinción de las simples uniones de hecho ${ }^{26}$. Respecto a su constitución, entrega el impulso de su reconocimiento a las propias parejas bajo la modali-

${ }^{25}$ Sobre la normativa autonómica actual de parejas de hecho y registros en España ver: Biedma Ferrer (2011), p. 207.

${ }^{26}$ Bossert y ZANONI (2004), p. 74. Según los autores por "uniones civiles" se entiende a aquellas uniones constituidas por personas de distinto o de igual sexo -parejas heterosexuales $u$ homosexuales- que conviven maritalmente en forma estable y que han formalizado y registrado esa unión y a quienes se les confieren derechos y deberes recíprocos. 
dad de uniones registradas, para este fin se crea un Registro público de uniones civiles, sin embargo, complementa esta modalidad con el establecimiento de determinados requisitos, que convertidos en impedimentos limitan el ingreso de parejas que no tengan una connotación afectivo-sexual ${ }^{27}$.

De la misma manera el caso de la República Oriental del Uruguay, con la dictación de la ley N N 18.246, denominada "Ley de Uniones Concubinarias". Esta entró en vigencia el 10 de enero de 2008. La propuesta asume un camino distinto estableciendo un estatuto de carácter imperativo, señalando con claridad los requisitos que han de estar presentes en la relación de afectividad, para que ésta pueda ser calificada como "pareja de hecho" susceptible de reconocimiento de efectos jurídicos ${ }^{28}$.

Esto tiene el mérito de solucionar integralmente gran parte del problema, otorgando una respuesta de carácter orgánico al fenómeno social, evitando la existencia de uniones que quedan al margen del Derecho, es decir, "uniones no juridificables".

Esta discusión tiene relevancia en el sistema propuesto en el proyecto de Acuerdo de Vida en Pareja (AVP), ya que éste por el contrario, traslada al impulso a los propios convivientes para el reconocimiento jurídico de su relación, otorgando la naturaleza de un contrato declarativo al instrumento que regula el nacimiento de las parejas frente al Derecho. El proyecto de AVP, con el resultado de la discusión en su primer trámite constitucional, mantiene el silencio respecto de esta situación, con ello gran parte del problema que ha justificado la necesidad de una regulación particular se mantiene ${ }^{29}$.

27 Señala el Artículo 10: "Unión Civil: A los efectos de esta Ley, se entiende por Unión Civil: a) a la unión conformada libremente por dos personas con independencia de su sexo u orientación sexual. b) Que hayan convivido en una relación de afectividad estable y pública por un período mínimo de dos años, salvo que entre los integrantes haya descendencia en común. c) Los integrantes deben tener domicilio legal en la Ciudad Autónoma de Buenos Aires, inscripto con por lo menos dos años de anterioridad a la fecha en la que solicita la inscripción. d) Inscribir la unión en el Registro Público de Uniones Civiles". Disponible en: http://www.cedom.gov.ar/es/legislacion/normas/leyes/ley1004.html [visitado 28/05/2014].

${ }^{28}$ La ley No 18.246 de "Uniones Concubinarias" de Uruguay, en su artículo No 1, señala: "La convivencia ininterrumpida de al menos cinco años en unión concubinaria genera los derechos y obligaciones que se establecen en la presente ley, sin perjuicio de la aplicación de las normas relativas a las uniones de hecho no reguladas por ésta". Por su parte, el articulo $N^{\circ} 2$ indica: "A los efectos de esta ley se considera unión concubinaria a la situación de hecho derivada de la comunidad de vida de dos personas -cualquiera sea su sexo, identidad, orientación u opción sexual-que mantienen una relación afectiva de índole sexual, de carácter exclusiva, singular, estable y permanente, sin estar unidas por matrimonio entre sí y que no resulta alcanzada por los impedimentos dirimentes establecidos en los numerales $1^{\circ}, 2^{\circ}, 4^{\circ}$ y $5^{\circ}$ del artículo 91 del Código Civil. Disponible en: http://www.parlamento.gub. uy/leyes/AccesoTextoLey.asp?Ley=18246\&Anchor= [visitado 28/05/2014].

${ }^{29}$ En la discusión en el senado la Comisión, por mayoría de votos, aprobó la siguiente norma: Artículo $1^{\circ}$.- "El Acuerdo de Vida en Pareja es un contrato celebrado entre dos personas con el propósito de 
Al no tratarse esta realidad con la suficiente extensión es posible prever la apertura de un nuevo conflicto jurídico, en cuanto surja la necesidad de requerir, respecto de las uniones sin estatuto, el cuestionamiento de la procedencia de la aplicación por analogía, del régimen de las uniones de hecho reguladas; de ser negativa la respuesta, esto abrirá las puertas a plantear la inconstitucionalidad de tales normas, al establecer un trato desigual entre unas y otras uniones.

Sin embargo, el camino adoptado por el AVP sustenta la posición de limitar la intervención legislativa del Estado respecto de aquellas parejas que voluntariamente se han mantenido al margen de todo estatuto, esto como muestra de respeto al derecho a la libre determinación de cada individuo, por cuanto de hacerlo se desnaturaliza a la unión de hecho, pasando a constituir una relación de Derecho ${ }^{30}$. No obstante, debemos clarificar que todo intento de regulación mantendrá el conflicto en uno u otro sentido, careciendo el Derecho comparado de un sistema que resuelva plenamente este problema ${ }^{31}$.

De esta manera, es posible reconocer en el Derecho comparado cuatro sistemas en función del tipo de regulación arbitrada a la convivencia no matrimonial, los cuales, al mismo tiempo, representan un orden cronológico de las diversas posiciones que se han asumido en la materia, estos son: a) países carentes de regulación; b) países que han aprobado leyes de parejas de hecho; c) países en donde se han aprobado leyes de uniones civiles homosexuales; d) países que han abierto la institución matrimonial a las parejas homosexuales.

\subsection{Una mirada desde la técnica legislativa para asumir su regulación}

Este renacer de las convivencias no matrimoniales en el Derecho ha sido abordado de distintas formas, reflejando en sí mismo la diversidad en la forma de concebir esta realidad social.

La técnica más generalizada ha sido el reconocimiento legal o constitucional, desarrollado a través de dos mecanismos: a) incorporación con un tratamiento orgánico y sistematizado; b) el reconocimiento de determinados efectos jurídicos en forma aislada, con orientación prioritaria a los efectos patrimoniales derivados de la convivencia ${ }^{32}$.

regular los efectos jurídicos derivados de su vida afectiva en común". En Primer Informe de la Comisión de Constitución, Legislación y Justicia, Senado de Chile, 11/12/2013. Disponible en: http://www. senado.cl/appsenado/templates/tramitacion/index.php\# [visitado el 28/05/2014].

30 En este sentido: Pantaleón Prieto (1998), pp. 71-72.

31 Sobre esta materia: VARAS BraUn (2010), pp. 9-22. Disponible en: <http://www.scielo.cl/scielo. php?script=sci_arttext\&pid=S0718-09502010000200001\&lng=es\&nrm=iso >. ISSN 0718-0950. http:// dx.doi.org/10.4067/S0718-09502010000200001 [visitado 28/05/2014].

32 Entre algunos de los países que han regulado en forma orgánica mediante su incorporación a la carta constitucional podemos señalar: Venezuela (art. 77), Brasil (art. 226), Bolivia (art. 194), Perú (art. 5º), 
En el Derecho comparado otros sistemas han resuelto el problema recurriendo a la aplicación por analogía de las normas del matrimonio, camino, por cierto, no exento de polémica en la dogmática jurídica. Este modelo, construido frente al vacío legal por falta de regulación, se fundamenta en una presunta identidad de razón entre ambas instituciones, asimilándolas en el factor de convivencia de carácter afectivo-sexual; esto surge en el contexto del principio de inexcusabilidad de los tribunales, quienes recurren a aplicar la norma por analogía, como una exigencia del principio de igualdad sin discriminación.

En una variante de esta posición se ha sostenido que, en el peor de los casos, frente a lagunas legales, de rechazarse esta identidad de razón, se puede recurrir a los principios generales del Derecho, extraídos de una o varias normas legales, sin excluir las relativas al matrimonio o al parentesco ("analogía iuris") 33 .

Otra forma está representada por la aceptación de pactos entre convivientes, esta modalidad ha tenido gran aceptación en Europa, y particularmente en España, por las distintas comunidades autónomas. En ella se otorga a los propios convivientes la posibilidad de que acuerden el régimen al que someterán su relación, extendiéndose desde su inicio hasta al período de ruptura. Este camino debió traspasar la barrera de las alegaciones en torno a la ilicitud de su causa, fundada en la valoración de connotación de naturaleza moral que pesó sobre las convivencias extramatrimoniales de ser contrarias al orden público ${ }^{34}$. Esta noción históricamente aceptada en algunos ordenamientos, llevó incluso a su sanción penal en algún momento, influyendo durante mucho tiempo en el criterio jurisprudencial, para enfrentar la validez de dichos pactos.

En la actualidad, la posibilidad de los convivientes de celebrar acuerdos, conforme al principio de la autonomía de la voluntad, no sólo es admitida, sino que tiene una gran aceptación en el ámbito de la regulación de los efectos patrimoniales de la pareja.

Paraguay (art. 51), Ecuador (art. 23). Como regulación en forma de ley: Suecia (mediante ley № 232/87 denominada del Hogar común de cohabitantes extramatrimoniales), Francia (ley No 99/944 de Pacto de Solidaridad, el 15 de noviembre de 1999), Argentina (La ley № 1004 de la legislatura federal de la ciudad autónoma de Buenos Aires de 2002), Uruguay (ley No 18.246 Ley de Unión Concubinaria, 10 de enero de 2008); Colombia (ley No 54 de 1990).

33 Gavidia SÁnChez (2004), pp. 1-24. Respecto de esta discusión se puede observar un análisis profundo a las diversas formas de aplicación analógica con el propósito de resolver conflictos que plantean las uniones de hecho frente a la ausencia de regulación expresa.

${ }^{34}$ En Francia se aceptaron previa discusión respecto de si era posible oponerlas a terceros; en Alemania se aceptan pactos patrimoniales no personales; en España con diversos matices diversas comunidades autónomas han aceptado esta vía como regulación. De VeRDA y BEAMONTE (2003), pp. 155-157. Sobre esta materia ver las referencias citadas en: Martínez De Aguirre Aldaz (2000), pp. 5-49. 
Un tercer conducto es dejar su regulación a la jurisprudencia. Así, quienes apoyan esta modalidad sostienen que mediante esta vía se evitaría directamente la discriminación, al no crear un matrimonio de segundo grado, de carácter poco igualitario para los convivientes, destacando además que esta vía permite una adecuada resolución, caso a caso, de los diversos conflictos ${ }^{35}$.

Sin embargo, podemos sostener que este estatuto es generador de incertidumbre e inseguridad jurídica, al no quedar definidas de antemano las pautas utilizadas por la judicatura, dejando a criterio del juez de turno la solución a los conflictos que se formulen, quienes al resolver recurren a distintas herramientas (tampoco definidas) frente a lagunas legales.

Entre los principales recursos a los que se acude podemos señalar: a) el recurso a la analogía, para sustentar el derecho a pensión compensatoria de uno de los miembros de la unión; b) la utilización del principio general del Derecho que prohíbe el enriquecimiento sin causa; c) la aplicación del principio de protección al conviviente más débil; d) el uso analógico del régimen matrimonial.

Debemos acotar que esta modalidad sustentada en la ausencia de regulación específica, se encuentra actualmente en retirada en el Derecho comparado, optando los diversos ordenamientos por asumir su regulación en forma específica y cada vez más orgánica, evitando la falta de uniformidad en las soluciones planteadas. No obstante, este conducto aún es común en países que han adoptado una postura abstencionista, como es el caso de Chile, en que no existe un reconocimiento expreso de estas uniones, generalmente sustentado en la defensa de la institución matrimonial como la forma en que naturalmente debe organizarse la familia.

No cabe duda que el criterio predominante hoy en día es una concepción pluralista del estatuto regulador de la familia, en que las parejas se enfrentan a diversas opciones que, junto al matrimonio, permitirán adecuar el orden jurídico a la libre determinación de cada individuo, con una alta influencia del principio de la autonomía de la voluntad-cada pareja tiene su régimen para sus necesidades-, reservando así la esfera del orden público para la figura matrimonial, para quienes opten por este sistema, con la salvedad, por cierto, de aquellos países en que se ha desestructurado de tal forma el matrimonio que actualmente la diferencia no es más que conceptual entre uno y otro régimen.

35 Esta posición es sostenida por Domínguez Hidalgo (2012), p. 3. 


\section{Juridificación de las Uniones de Hecho en Chile}

Las uniones de hecho en Chile no han tenido nunca un tratamiento orgánico y particular de sus efectos. El Código Civil vigente desde 1857, inspirado en el Derecho romano, canónico y en el Código Civil francés, no dio regla alguna sobre las relaciones no matrimoniales, limitándose en parte del Mensaje con que se remite el proyecto al Congreso, a utilizar términos como concubina y barragana, al referirse a la legitimación de la filiación ${ }^{36}$.

A lo largo del siglo XIX no se reglamentó la convivencia, salvo alguna mención aislada en la legislación penal que dejó de manifiesto el rechazo social existente, esto como reflejo de la fuerte estigmatización en aquella época, pues los que demostraban públicamente su convivencia eran considerados "pecadores públicos" y atraían sobre sí la repulsión de las autoridades eclesiásticas y de la población civil ${ }^{37}$.

Analizando la situación de los sistemas jurídicos latinoamericanos se llega a la conclusión de que Chile es uno de los últimos ordenamientos que actualmente no ha regulado de manera específica este fenómeno. No obstante, la realidad de la sociedad chilena no es diferente a la de otros países ${ }^{38}$.

Cabe aclarar que Chile es uno de los estados en que los cambios que ha experimentado el Derecho de Familia se han asumido de manera más lenta en el ámbito del Derecho occidental. Sólo a modo de orientación, en épocas en que el divorcio estaba omnipresente en todos los ordenamientos jurídicos, Chile sin concordato de por medio no lo introdujo en su legislación sino hasta el año 2004, manteniendo aún conceptualmente un matrimonio de carácter indisoluble dentro de su Código Civil ${ }^{39}$.

En esta secuencia, Chile mantuvo su silencio sin pronunciarse respecto de las relaciones convivenciales durante un largo tiempo. Esta posición no deviene

\footnotetext{
${ }^{36}$ Andrés Bello, redactor del Código Civil chileno, a propósito de las reglas de filiación que clasificaban a los hijos en legítimos, naturales e ilegítimos, menciona el concepto de concubina y barragana, este último vinculado al tratamiento conceptual que durante la Edad Media se le da al concubinato, cuya mención llega al ordenamiento jurídico de Chile desde el Código de las Partidas.

37 El Código Penal de 1875 tipificó el delito de amancebamiento respecto del marido que mantenía una relación de convivencia con una persona casada, ya sea dentro de la casa conyugal o fuera de esta con escándalo.

${ }^{38}$ En Chile las cifras muestran un fuerte descenso en el número de matrimonios celebrados, aumento generalizado en todos los estratos sociales de las convivencias no matrimoniales ya no asociado únicamente a sectores marginales o a causas de pobreza, sino que surge un nuevo grupo con mayor educación y de estratos socioeconómicos superiores. Para analizar datos sociológicos ver: RodRícuez (2004). De la misma manera Binstock (2009).

39 García Cantero (2010), p. 12.
} 
de la simple indiferencia, sino en forma deliberada y consciente, inspirada en el espíritu de la legislación de la época, induciendo a las personas a recurrir a la institución matrimonial como único estatuto generador de derechos y obligaciones ${ }^{40}$.

Debemos destacar que la posición abstencionista del Estado actualmente no resulta indiferente, considerando el proceso de constitucionalización que atraviesa el Derecho en general, pero particularmente respecto al Derecho de Familia. En este sentido, cada vez son más las voces que sostienen que en este silencio existiría una transgresión abierta a los derechos humanos consagrados a nivel constitucional, provenientes en gran parte de las directrices contenidas en instrumentos internacionales, cuyo respeto y promoción constituye el sustrato básico de un gobierno democrático ${ }^{41}$.

Esta postura abstencionista dará paso lentamente a una apertura frente al fenómeno; a partir de mediados del siglo XX la legislación comenzará a manifestarse, exclusivamente respecto de la convivencia de personas de distinto sexo, con una tendencia a evitar la perspectiva de recriminación. Este proceso denota un desplazamiento progresivo de la terminología "concubinato" a la de "convivencia" 42.

Este devenir no logrará alcanzar una regulación estatutaria. Durante este período surgen diversos pronunciamientos jurisprudenciales que generarán una respuesta relativamente estable para los principales problemas, esto generalmente a partir de la resolución de conflictos patrimoniales que se originan en la ruptura. Esta práctica judicial se presentará como fuente de un cierto reconocimiento jurídico, frente al silencio de la voluntad del legislador.

Los principales problemas que han conocido los tribunales chilenos se pueden resumir en: a) situación patrimonial de la pareja al término de la convivencia; b) legitimación activa para demandar indemnización de perjuicios por daño moral en el caso de un ilícito que causa la muerte de la pareja; c) si el concubinato constituye título suficiente para enervar la acción de precario intentada por un exconcubino cuando terminada la relación su pareja ocupa

\footnotetext{
40 Meza Barros (1975), p. 398.

${ }^{41}$ Para mayor profundidad sobre el tema ver: TAPIA RodríGuez (2007), p. 160. Del mismo modo Hernández Paulsen (2007).

${ }^{42}$ Barrientos Grandon (2006), p. 3. En Chile en este período la ley No 9.293, de 19 de febrero de 1949, fue la primera en reconocer expresamente un efecto jurídico al concubinato, al introducir el artículo 14 de la ley $\mathrm{N}^{\circ}$ 5.750, de 30 de noviembre de 1935, sobre "Abandono de familia y pago de pensiones alimenticias", una disposición que hacía solidariamente responsable del pago de la obligación alimenticia a quien viviera en concubinato con el padre, madre o cónyuge del alimentario.
} 
un inmueble de su propiedad y d) existencia de una relación laboral ${ }^{43}$. Durante los últimos años, además, se han debido pronunciar sobre otras materias como: la procedencia de la compensación económica ${ }^{44}$ y violencia intrafamiliar entre convivientes del mismo sexo ${ }^{45}$.

Paralelamente, se dictarán leyes que en forma aislada reconocerán determinados efectos jurídicos, situación que al día de hoy configura un sistema disperso de reconocimiento limitado en variadas materias ${ }^{46}$. En la actualidad aún existen vacíos elementales sin regulación, a modo de ejemplo, el ordenamiento jurídico actualmente no aporta una definición del concepto de uniones de hecho, siendo la doctrina quien se ha encargado de hacer su aporte, mientras los tribunales han definido, con divergencia, los elementos que estructuran las uniones de hecho o concubinato ${ }^{47}$.

Podemos reconocer en esta época, en términos prácticos, dos formas de concubinato diferenciados por sus causas, estos son: a) las convivencias afectivas cuya causa era el matrimonio religioso, esto como consecuencia fáctica generada en la dictación de la Ley de Matrimonio Civil de $1884^{48}$; b) aquellas uniones cuya causa sólo se hallaba en el hecho afectivo, en este grupo podemos distinguir aquellos que voluntariamente se mantienen al margen del ordenamiento; y aquellos que se encuentran al margen por impedimento legal ${ }^{49}$.

43 Esta etapa reflejará similitud con el fenómeno ocurrido en España, previo a la dictación de leyes autonómicas en las diversas comunidades, por cuanto se recurrió a utilizar las normas generales del Derecho Civil entre las que destacan las normas de la comunidad, sociedad de hecho, responsabilidad extracontractual; o bien, los principios generales del Derecho como el enriquecimiento sin causa.

${ }_{44}$ Ver: Sánchez Ponce, Rosa con Sucesión Parada Merino (2012): Corte Suprema de Chile, 7 de marzo de 2012 (Recurso de Casación de forma y de fondo), rol № 337-2011.

${ }^{45}$ Ver: Corte de Apelaciones de La Serena, enero de 2007 (Recurso de Nulidad), rol № 373-2006.

${ }^{46}$ Entre las normas legales que reconocen jurídicamente a quienes viven en convivencias: acciones de reclamación de paternidad; el derecho a la no autoincriminación; en materia de violencia intrafamiliar; la atenuante de la vindicación próxima de una ofensa grave causada al conviviente; el que el conviviente no está obligado a declarar como testigo en juicio oral; la incorporación dentro del Parricidio como autor al conviviente.

47 A modo de ejemplo, Bejarano y otros con Araya (1997): Corte de Apelaciones de Valparaíso, 15 de septiembre de 1997, en: Gaceta Jurídica 206, p. 90, señala como elementos constitutivos: a) unión entre un hombre y una mujer; b) relaciones sexuales; c) vida en común; d) continuidad, estabilidad y permanencia de todos estos elementos. En cambio en Hidalgo Osorio María con Misa Toro Gilda (1987): Corte de Apelaciones de Valparaíso, 23 de junio de 1987, en: Gaceta Jurídica 85, p. 50, además de los mismos requisitos señalados en el fallo anterior, agrega la publicidad o notoriedad en la vida común.

${ }^{48}$ La Ley de Matrimonio Civil promulgada el 16 de enero de 1884 vino a regular el matrimonio de los no católicos, sus solemnidades y efectos. El artículo $1^{\circ}$ de la ley era muy claro al disponer que "el matrimonio que no se celebre con arreglo a las disposiciones de esta lei, no produce efectos civiles".

49 Barrientos Grandon y Nóvales Alquézar (2004), p. 65. 
Parte de la doctrina sostiene que la razón del reconocimiento de la unión de hecho, como una construcción jurisprudencial, halla justamente su raíz en la dictación de la Ley de Matrimonio Civil de 1884, la que originó un conflicto en los matrimonios religiosos que no habían contraído este vínculo ante la ley civil, cuestión que ocurrió por un acto de desconocimiento de la nueva ley, o bien, como una forma de protesta frente a la nueva realidad al margen de la autoridad eclesiástica, esto dio lugar a múltiples uniones no matrimoniales ${ }^{50}$.

Junto a lo anterior, recién en el año 2004 Chile accede a la figura del divorcio vincular. Durante un largo período existió un impedimento legal, como generador de uniones no matrimoniales, es decir, al no existir divorcio, existe imposibilidad involuntaria de los separados de hecho, restringiendo el acceso de parte de la población al matrimonio. Sin embargo, al incorporarse la figura del divorcio bajo requerimiento de acreditar un plazo de cese efectivo de la convivencia, no se resuelve íntegramente el problema, ya que muchas parejas se verán transitoriamente obligadas a convivir sin matrimonio, en espera a que se computen los plazos que la ley establece ${ }^{51}$.

Turner, considerando este escenario, postula que los verdaderos destinatarios de una regulación legal de la unión de hecho en Chile serían las parejas que no pueden acceder al régimen matrimonial, con mención especial de las parejas entre personas del mismo sexo ${ }^{52}$.

En el ámbito legislativo no han sido pocos los intentos de juridificación, sin que existiese el consenso político necesario para aprobarlo, lo que provocó que estos intentos concluyeran sin éxito, o bien, estuvieren durante largo tiempo sin tramitación ${ }^{53}$.

El 17 de agosto del año 2011 se remite al Congreso por parte del Ejecutivo el Proyecto de Ley de AVP (Boletín № 7873-07), actualmente en primer trámite legislativo. Respecto a la viabilidad de este proyecto existen diversas razones que permiten garantizar su buen término, entre las que podemos destacar:

a) El compromiso asumido por los diversos sectores políticos, quienes han considerado el factor sociológico, relacionado al elevado número de ciudadanos que actualmente declaran convivir en una relación no matrimonial.

\footnotetext{
50 LATHROP GÓMEZ (2009).

51 Mesa Marrero (2006), p. 25.

52 Turner Saelzer (2007), pp. 167-176.

53 Respecto a las iniciativas legislativas, durante los últimos 20 años existen diversas mociones parlamentarias de las cuales se encuentran varias archivadas y otras actualmente en tramitación, la primera de ellas fue ingresada el 15 de octubre de 2003 (Boletín 3377-03), fue archivado luego de dos años sin tramitación; de ahí, más de ocho proyectos legislativos correrán distinta suerte, hasta el actual proyecto de AVP, ingresado el 17 de agosto del año 2011.
} 
b) La circunstancia que el proyecto de ley fue remitido por el sector político, que siempre ha representado la mayor oposición a la regulación de la convivencia no matrimonial ${ }^{54}$.

c) La fuerte presión del colectivo homosexual, a quienes se le ha comprometido una forma de regulación que mejore su situación, sin que ello signifique acceso al matrimonio.

d) Finalmente, se debe considerar la situación actual del Derecho Matrimonial en Latinoamérica y la presión que ello ejerce en los diversos gobiernos $^{55}$.

Si bien este no es el primer proyecto sobre la materia que se tramita en el Congreso chileno, es el que representa la posibilidad cierta de que por primera vez se legisle sobre la materia.

\section{El Proyecto de ley que Crea el Acuerdo de Vida en Pareja en Chile}

El proyecto de AVP representa quizás una de las reformas de mayor envergadura al Derecho de Familia chileno, ya que viene a consagrar un reconocimiento jurídico amplio del concepto de familia. Este criterio ya incorporado en la legislación nacional, a partir de la Ley de Matrimonio Civil del año 2004, ha sido asumido mayoritariamente a nivel de la doctrina nacional ${ }^{56}$. Teniendo presente esta concepción, el proyecto de ley viene a dar eficacia a la obligación del Estado establecida a nivel constitucional, de proteger y fortalecer la familia generada a partir de las uniones de hecho ${ }^{57}$.

\footnotetext{
${ }^{54}$ Ver a modo de ejemplo, la tramitación de dos proyectos de ley que buscaban la regulación de las uniones de hecho en Chile, proyectos signados como Boletines $N^{\circ}$ s 4153-18 y 4187-18, en Informe de la comisión de familia, recaído en dos proyectos de ley que establecen regulación para las uniones de hecho, Cámara de Diputados, 26 de junio del 2009.

55 Como se indicó, la totalidad de los países latinoamericanos han regulado las uniones de hecho, y existen tres países que han incorporado el matrimonio homosexual, estos son Argentina (Ley Nacional № 26.618), México (Ley de alianza entre personas del mismo sexo, 21/12/2009) y recientemente Uruguay (Ley de Matrimonio Igualitario, 10/04/2013).

${ }^{56}$ La ley No 19.947 del año 2004, en el inciso primero del artículo № 1 establece: "La familia es el núcleo fundamental de la sociedad. El matrimonio es la base principal de la familia". La alusión al matrimonio, como base principal, convoca la existencia de otras formas familiares, cuyo origen no son la institución matrimonial. Algunos autores que postulan dicha opinión: FigueroA Yáñez (1995), pp. 70-72.; Peña González (1996), pp. 140-150; Ramos Pazos (2006), pp. 12-13; BarRientos Grandon (2004), pp. 472; Sin embargo, es de la opinión contraria CoRRAL TALCIANI (1994), pp. 140-150.

57 Sobre esta materia: TAPIA RodRíguez (2007), pp. 160-161. Sostiene que esto responde a un proceso en que se modifica progresivamente la visión unívoca y normativa de la familia, por una regulación que no busca establecer un modelo de relaciones familiares, sino que pretende abrir espacios para diferentes proyectos de vida y convicciones morales. Esta mirada, asume la nota funcional de los diferentes proyectos de vida de los individuos: "a cada uno su familia, a cada uno su derecho".
} 
Debemos advertir que la posición que reconoce a la familia en los modelos extramatrimoniales no es una cuestión pacífica a nivel doctrinal, sin embargo, gran parte de la discusión respecto al enfoque del AVP se alza frente a la posición que emana del Mensaje del propio proyecto, el cual indica: "tal como señalamos en nuestro programa de gobierno, la familia se manifiesta a través de distintas expresiones"; continúa en el mismo sentido, "pero además, existen otros grupos familiares, como los monoparentales, los de familias extendidas, los formados por las parejas de convivientes y aquellos formados por parientes consanguíneos".

Esta premisa acentúa una mirada pluralista respecto al modo de enfrentar la regulación de lo que constituye familia para el Derecho. Asimismo, reconoce la libre determinación de las personas para optar a la estructura familiar que mejor les acomode para su proyecto de vida. Desde esta mirada, el Estado se presenta como neutral frente a la funcionalidad que cada modelo representa, permitiendo que cada individuo se conforme como un fin en sí mismo, y no como un medio para los fines de la colectividad. El reconocimiento jurídico de diversidad de los modelos familiares se proyecta como un indicativo del incremento de las opciones y el resultado de las elecciones individuales.

En esta perspectiva existe una clara manifestación de la filosofía liberal individualista, que impregna el modo de pensar en las sociedades postmodernas, cuyos principios básicos giran en torno a la autodeterminación de la persona y su supremo derecho a la libertad. En este sentido, el tribunal constitucional ha señalado que estos postulados "configuran principios y valores básicos de fuerza obligatoria que impregnan toda la Constitución de una finalidad humanista que se irradia en la primacía que asignan sus disposiciones a la persona humana, a su dignidad y libertad natural, en el respeto, promoción y protección a los derechos esenciales que emanan de la naturaleza humana, que se imponen como deber de los órganos del Estado" ${ }^{\prime \prime 5}$.

Estos valores rectores no configuran meras declaraciones programáticas, sino que constituyen mandatos expresos para el Estado; precisamente por ello es que la familia constitucionalmente protegida y formalmente desvinculada del matrimonio justificaría la concesión de derechos a los convivientes. De esta manera, resulta posible comprender como discriminatorias aquellas medidas que teniendo como fin la protección de derechos, excluyan la convivencia no matrimonial. Por esta vía, incluso es entendible que los efectos jurídicos pre-

${ }^{58}$ Requerimiento de inconstitucionalidad deducido por Carlos Ominami Pascual respecto de los artículos 2331 del Código Civil y 40, inciso segundo, de la ley № 19.733, sobre libertades de opinión e información y ejercicio del periodismo, rol № 1185 (2008): Tribunal Constitucional de Chile, 16 de abril del 2009, considerandos 11 y 12. 
vistos para el matrimonio puedan trasladarse a las parejas de hecho, tal como ha ocurrido en una cantidad importante de ordenamientos.

En este contexto, la labor que se le asigna al Derecho de Familia no es la de estructurar normativamente un modelo de vida por sobre otros, sino la de tutelar en un plano de igualdad y respeto, dentro de las limitaciones existentes en el ordenamiento jurídico, respetando la libertad de cada persona. Igualmente, resultaría injustificada la situación privilegiada del matrimonio por sobre otros estatutos, en la medida que su justificación se sostiene en instrumentalizar al individuo, en miras de los objetivos funcionales que le asigna el Estado para sus propios fines.

Bajo la concepción humanista de nuestra constitución, se enfatiza el enfoque sobre la persona en el carácter de sujeto y no objeto del derecho. Es así como los atributos básicos de la persona se encuentran consignados en el artículo $1^{\circ}$ de la Carta Fundamental que, como ha sostenido el Tribunal Constitucional "es de un profundo y rico contenido doctrinario, que refleja la filosofía que inspira nuestra Constitución y orienta al intérprete en su misión de declarar y explicar el verdadero sentido y alcance del respeto de la preceptiva constitucional"; de esta manera se consagra el carácter de seres dignos, libres e iguales, caracterizando a cada persona en el ámbito de la sociabilidad, factor inherente y que constitucionalmente se expresa en que "la familia es el núcleo fundamental de la sociedad"159.

El proyecto de AVP forma parte del programa de gobierno del presidente Sebastián Piñera Echeñique para el período 2010-2014, quien durante su campaña manifestó claras intenciones de regular los aspectos patrimoniales que implican las convivencias no matrimoniales, en este sentido señalaba: "También nos ocuparemos de los dos millones de chilenos que conviven en pareja sin estar casados".

La referencia a las uniones de hecho como conducta generalizada de la población para justificar la necesidad de un estatuto particular ha dividido a la doctrina en cuanto a la relevancia que jurídicamente representa este factor para el Derecho. Por un lado se alude a que la pretensión de buscar siempre que las situaciones fácticas se conviertan en objeto del Derecho llevaría a una permanente espiral legislativa $\sin \mathrm{fin}^{60}$.

\footnotetext{
${ }^{59}$ Requerimiento de inconstitucionalidad deducido en contra de algunas disposiciones de las "Normas Nacionales sobre Regulación de la Fertilidad", aprobadas por el Decreto Supremo № 48 de 2007 del Ministerio de Salud, (2008): Tribunal Constitucional de Chile, rol № 740/ 2007, 18 de abril del 2008, considerandos 46 y 47.

${ }^{60}$ En la tramitación actual del proyecto, gran parte de la discusión se centra en la eficacia de regular la materia, teniendo presente los datos estadísticos que dan cuenta de los altos porcentajes de convivientes y de bajos índices de parejas que celebran el pacto una vez legislado sobre la materia; así se
} 
Se afirma que la norma no puede ser mera traducción a términos jurídicos de lo que acontece en el diario quehacer social, "No es mera legalización de lo que ha sucedido o está sucediendo en la vida real", así sobrarían, en tal caso, los órganos legislativos y todo sería costumbre o uso social, o bien, un hecho jurídico, convertido automáticamente en regla de Derecho ${ }^{61}$.

Podemos replicar que la razón no se encontraría en una exacerbada reacción que lleva a establecer un estatuto para las uniones de hecho con ocasión de su generalidad, sino, como se ha indicado, su verdadera justificación se halla en el carácter de familia que conforman estas uniones, y en la obligatoriedad que tiene el Estado de otorgar protección y fortalecimiento como núcleo privilegiado de la sociedad; se trata en último término -tal como lo indica el proyecto de AVP_ "en la obligación que pesa sobre el Estado de orientar cada una de sus actuaciones a la obtención del bien común, como fin garantizado constitucionalmente".

La posición del legislador no debiera orientarse en la indiferencia o la reacción, sino hacia una reflexiva observación de los cambios sociales, por cuanto se trata de comportamientos que se reiteran con frecuencia, que no pueden ser ignorados indefinidamente por el Derecho; si bien el ordenamiento se sustentaba en un comportamiento tipo; se producen cambios sociales tan radicales, que las conductas que resultaban excepcionales, pasan a ser asimiladas por la conciencia social, exigiendo una adecuada respuesta jurídica, que permita dar legitimidad y eficacia a la regulación normativa.

\subsection{Un proyecto de insuficiencias, la familia convivencial y sus efectos limitados}

El estado actual de la respuesta que entrega el Derecho chileno a las uniones de hecho, sustentada en la visión jurisprudencial del Derecho de las obligaciones, se torna insuficiente, reclamando la institución para sí un estatuto particular suficiente. Estamos de acuerdo en que, una vez determinada la obligación del Estado sobre la familia no matrimonial, resulta un imperativo su protección y fortalecimiento, en un plano de igualdad respecto de otros modelos ${ }^{62}$.

puede observar en la intervención del representante de la Organización Acción Familia; intervención de la señora Ministra Secretaria General de Gobierno; intervención representante de Red por la Vida y la Familia. Primer Informe de la Comisión de Constitución, Legislación y Justicia, Senado de Chile, 11/12/2013. Disponible en: http://www.senado.cl/appsenado/templates/tramitacion/index.php\# [visitado el 26/5/2014].

${ }^{61}$ García Cantero (1982), pp. 193-213.

62 Turner Saelzer (2007), pp. 167-176. 
Dentro del Mensaje Presidencial con que se remitió el proyecto para su tramitación se señala que se reconoce en la familia "en sus distintas expresiones (...) el lugar donde por esencia, los ciudadanos se forman, y reciben y dan amor, acogimiento y formación", continúa señalando "[D]esde siempre, ha sido en la familia donde se estructuran las primeras relaciones intergeneracionales, se enseñan y transmiten valores fundamentales para el desarrollo individual y la realización personal, como el amor, la lealtad, la gratuidad, la solidaridad, la laboriosidad y la cooperación; y se desarrollan las pautas morales y sociales de conducta".

Esta declaración contiene las funciones estratégicas de la familia, es decir, aquellas razones que justifican la preocupación prioritaria por parte del Estado, la sociedad y el Derecho; esto se materializa en una regulación jurídica específica y en la consagración de su protección a nivel constitucional. En ello se encuentra la justificación de la existencia de un Derecho de Familia, al intentar proponer un sistema estructurado para fortalecer e incentivar este grupo intermedio que cumple funciones consideradas vitales para la sociedad.

Desde esta mirada, la familia se observa como un grupo humano de interés social primario, debido a sus funciones en relación con la sociedad, concibiéndose como "una estructura de humanización y socialización barata, eficaz, al alcance de prácticamente cualquier ciudadano y por ello mismo masiva"63. Justamente, estos argumentos inspiran aquella posición que no justifica la preocupación que muestra el Derecho por este tipo de uniones, por cuanto estas relaciones de afectividad no comprometidas no despliegan todas sus virtudes en beneficio de la comunidad; a su favor se aluden estudios que indican respecto de las convivencias: bajas tasas de natalidad, inestabilidad y poca duración ${ }^{64}$.

Por ello, se asume críticamente el sentido jurídico de incorporar a las parejas homosexuales como sujetos de regulación particular; ya que este tratamiento específico del Derecho sólo se justificaría en la medida que estas relaciones de carácter afectivo-sexual puedan cumplir con el fin de fortalecer el modelo social. Sobre esta base, el elemento sexual sólo resultaría relevante en la medida que cumpla el fin de reproducción, permitiendo la continuidad del grupo humano, su cultura y valores, elementos indispensables para la subsistencia de cualquier colectividad ${ }^{65}$.

En un sentido adverso, podemos señalar que esta mirada funcional de la persona, que levanta diferencias entre las parejas por razones de sexo, fundadas

\footnotetext{
63 Martínez De Aguirre Aldaz (2007), p. 714.

${ }^{64}$ Para un aporte interesante con base en estadísticas de la situación en diversos países ver: CORRAL Talciani (2012), p. 4. En el mismo sentido véase: Martínez De Aguirre Aldaz (2000), pp. 719-721.

${ }^{65}$ Sobre esta materia ver: Del Picó Rubio (2011), pp. 31-56.
} 
en la imposibilidad de procreación, se opone manifiestamente a las bases de la institucionalidad sobre las que se cimenta nuestra Carta Fundamental, principalmente por cuanto no se concibe al Estado como un fin en sí mismo, sino como un medio cuya orientación es el desarrollo integral de cada uno de los individuos, en esto yace el propósito del Estado, que no es otro que alcanzar el bien común ${ }^{66}$.

En el Derecho occidental moderno, paulatinamente, se han abandonado aquellas concepciones que priorizan la procreación como elemento esencial de la familia jurídica, esto bajo la mirada de un bien común personalista, sustentado en la necesidad de conformar familia, como una cuestión asociada a la dignidad humana, protegida y garantizada por el sistema universal de Derechos Humanos. De este modo, actualmente la facultad de engendrar tampoco es requisito del matrimonio, institución que de manera transversal ha representado el concepto de familia; así, la actual Ley de Matrimonio Civil, al regular las causales de nulidad, eliminó la impotencia como factor preponderante; por tanto, mal puede constituirse en un factor diferenciador de efectos jurídicos.

Ahora bien, la incorporación de las parejas homosexuales como sujetos capaces para la celebración del AVP tiene la trascendencia de cambiar la orientación que hasta la fecha le ha otorgado la fuente jurisprudencial a los requisitos constitutivos de las convivencias no matrimoniales, cuyo criterio general es la diferencia de sexo, salvo alguna situación excepcional ${ }^{67}$.

En este camino, podemos indicar que los propósitos tras la regulación de las uniones no matrimoniales difieren de los objetivos planteados en la institución matrimonial, con ello no se intenta crear un matrimonio de rango inferior, sino dar soluciones legales a problemas económicos primarios, en materias en las que debe prevalecer la necesidad de protección, y, en último caso, el requerimiento de proveer de un estatuto suficiente que otorgue estabilidad a la familia convivencial.

${ }^{66}$ El Tribunal Constitucional en Sentencia, rol № 740/ 2007, considerandos 47, ha declarado: "Una última característica de la persona puede ser advertida en el contexto de los valores y principios recogidos en el artículo $1^{\circ}$ de la Constitución. Se trata de que la persona está dotada de materia y espíritu, pues al definir el bien común o fin del Estado, la Carta Fundamental impone a éste no sólo el deber de estar al servicio de la persona humana sino que, además, de "contribuir a crear las condiciones sociales que permitan a todos y a cada uno de los integrantes de la comunidad nacional su mayor realización espiritual y material posible, con pleno respeto a los derechos y garantías que esta Constitución establece".

${ }^{67}$ Ver: Sánchez Ponce, Rosa con Sucesión Parada Merino (2012): Corte Suprema de Chile, 7 de marzo de 2012 (Recurso de Casación de forma y de fondo), rol No 337-2011; Sentencia de la Corte de Apelaciones de Santiago, rol № 38-2013, del 15 de marzo del año 2013; Bejarano y otros con Araya (1997): Corte de Apelaciones de Valparaíso, 15 de septiembre de 1997, en: Gaceta Jurídica 206, p. 90. Como excepción, la Corte de Apelaciones de La Serena conociendo un recurso de nulidad interpuesto por el condenado por violencia intrafamiliar (rol № 373-2006), acogió el concepto de convivencia entre personas del mismo sexo. 
Debemos señalar que el proyecto de AVP durante su tramitación se ha despojado de las contradicciones que presentaba el proyecto inicial. Esto ha permitido armonizar el reconocimiento de su carácter de familia a las uniones de hecho con la estructura propuesta para su regulación. Esto queda de manifiesto en dos elementos relevantes: a) el régimen patrimonial propuesto, el que se sustentaba originalmente en una restringida comunidad limitada a los bienes muebles sujetos a inscripción ${ }^{68} \mathrm{y} ;$ b) en el tratamiento de los efectos personales asignados al estatuto; muy restringidos dentro del proyecto inicial enviado por el ejecutivo.

Si los convivientes celebraran el AVP, en la forma que contemplaba el proyecto originario, solo tendrían comunidad legalmente reconocida sobre los bienes muebles sujetos a inscripción; excluyendo así los bienes de mayor relevancia para el sostén del grupo familiar, como son los bienes inmuebles y en particular la residencia familiar. Esta manera de abordar el asunto planteaba una clara contradicción, considerando los argumentos orientadores del proyecto.

Situadas las uniones de hecho dentro del contexto de familia, resulta de plena lógica que para la resolución de sus problemas se implemente un sistema regido por el principio de solidaridad propio del Derecho de Familia, relevando la obligación de cuantificar y probar los aportes respectivos de cada conviviente, permitiendo de antemano una distribución por partes iguales de las ganancias existentes a la ruptura, sin tener en consideración el aporte efectivo realizado por cada miembro, como ocurre en la actualidad al aplicar las reglas del Derecho Patrimonial común ${ }^{69}$.

Tal como señalamos, el proyecto se presentaba en su contenido programático como un modelo de carácter proteccionista, cuyo propósito primordial es regular aspectos patrimoniales que surgen con ocasión de la convivencia, proponiendo un sistema alternativo y de menor jerarquía frente al matrimonio, fundado en el elemento de la funcionalidad que representa cada realidad.

Respecto a su regulación, se enmarca dentro del modelo de pareja inscrita o formalizada en documento público, sistema que se sustenta en una declaración expresa de los convivientes, quienes deben manifestar inicialmente su voluntad para incorporarse al régimen jurídico que el legislador pone a su

\footnotetext{
${ }^{68}$ Durante la tramitación del proyecto, la Comisión por mayoría de votos aprobó ampliar el régimen de comunidad a toda clase de bienes que se adquieran a título oneroso durante la vigencia del acuerdo. En Primer Informe de la Comisión de Constitución, Legislación y Justicia, Senado de Chile, 11/12/2013. Disponible en: http://www.senado.cl/appsenado/templates/tramitacion/index. php\# [visitado el 28/5/2014].

${ }^{69}$ Turner Saelzer (2007), p. 91. Propone que al situar las uniones de hecho en el Derecho de Familia, la solución a los conflictos suscitados por la ruptura de la pareja debiese tener coherencia con lo que ocurre en el régimen matrimonial, en la división por partes iguales de las ganancias obtenidas durante la vida en común, sin considerar los aportes que cada miembro de la unión haya hecho efectivamente.
} 
disposición. Esta declaración tendrá además carácter formal, ya que para la eficacia de las reglas previstas se requiere que la voluntad de la pareja conste en documento público y sea objeto de inscripción, con carácter constitutivo en registro público ${ }^{70}$.

Las reglas previstas para este modelo constituyen un verdadero estatuto jurídico predispuesto al que las partes se adhieren de manera voluntaria, y que incluye mayoritariamente reglas de carácter imperativo, porque forman parte del entramado de derechos y deberes, institucionalmente configurado por el legislador que las partes asumen mediante su declaración constitutiva ${ }^{71}$. El modelo propuesto se acerca al sistema francés propuesto en el PAC, estableciendo un marco regulatorio al que pueden optar voluntariamente los convivientes sin distinción de sexo para regular su vida en común, mediante el establecimiento de un régimen contractual ${ }^{72}$.

EI PAC en su inicio propuso que mediante la autonomía de la voluntad los convivientes puedan regular sus relaciones exclusivamente de carácter patrimonial (al igual que el proyecto de AVP), así, inicialmente se distanciaba del establecimiento de obligaciones personales, como la modificación del estado civil, el cambio de nombre de los convivientes, cuestión que sí ocurre en dicho país con el matrimonio, tampoco se establecían deberes de fidelidad ni referencia a las obligaciones de respeto mutuo, aún cuando en esta materia, se acude a la legislación de carácter especial que sanciona la violencia al interior de la familia ${ }^{73}$.

Sin embargo, debemos señalar con Belluscio que el proyecto inicial ha sido modificado por la ley francesa 2006-728, reformatoria del código civil. Mientras que en el texto inicial se limitaba a disponer que las partes se aportasen ayuda mutua, ahora el nuevo párrafo del artículo establece que se comprometen a una vida común, lo mismo que a una ayuda material y asistencia recíprocas, con lo que se crean, como deberes inherentes al pacto, los

${ }_{70}$ Luego de la discusión en el senado, dispone el Artículo $5^{\circ}$.- Tanto el acta levantada por el Oficial del Registro Civil como la escritura pública en la que conste el Acuerdo de Vida en Pareja sólo tendrán existencia entre las partes y respecto de terceros desde que se inscriban en un registro especial que Ilevará el Servicio de Registro Civil e Identificación. El plazo para solicitar su registro será de 10 días hábiles contado desde su otorgamiento, a petición de cualquiera de los contratantes. Disponible en: http://www.senado.cl/appsenado/templates/tramitacion/index.php\# [visitado el 28/5/2014].

71 Sobre los distintos modelos de regulación de las uniones de hecho ver: Martin CaSAls (2013), pp. 12-15.

72 Michel Grimaldi (2004), p. 2. El PAC así planteado "responde, al mismo tiempo, a la demanda de heterosexuales que podrían casarse, pero que no lo quieren, y a la demanda de homosexuales que quisieran casarse, pero que no pueden hacerlo".

73 Figueroa Yáñez (2005), p. 443. 
de cohabitación, asistencia material y moral, acercándose paulatinamente a la institución matrimonial ${ }^{74}$.

En un camino distinto se encuentra el modelo predominante en los países nórdicos, en que se establecen regulaciones diferenciadas, reconociendo naturalezas distintas respecto de parejas heterosexuales u homosexuales; en estos últimos, la tendencia es hacia un sistema de características análogas al matrimonio, con regulación de obligaciones de carácter personal, bajo la lógica de otorgar un marco jurídico de jerarquía y eficacia, similar al matrimonio para quienes no pueden acceder a él porque la ley se los prohíbe ${ }^{75}$.

Mientras la propuesta legislativa del AVP se distancia de esta última concepción, el proyecto legislativo fundamenta: "Al proceder de esta manera lo hacemos honrando una convicción muy profunda de nuestro gobierno, en el sentido de que el matrimonio corresponde a un contrato que por su naturaleza, debe ser celebrado entre un hombre y una mujer". Este paradigma, que orienta el proyecto legislativo, permite entender los esfuerzos por mantener una distancia clara entre las uniones de hecho y el matrimonio, justificando al mismo tiempo el carácter patrimonial al que limita su objeto de regulación.

Esto sitúa la propuesta legislativa dentro del tipo denominado "Leyes de Parejas de Mínimos", pues propone regular las relaciones de afectividad sin cuestionar la supremacía del matrimonio, provocando que en muchas aristas se presente como ambiguo y poco eficaz, por cuanto, pese a estar destinado a resolver la demanda de la comunidad homosexual, el modelo resulta poco atractivo, siendo estos sujetos los que menos utilizan el estatuto ${ }^{76}$.

Según Bascuñán, el proyecto de AVP obedece más bien a un proyecto de naturaleza "híbrida", por tanto confunde conceptos de ambas orientaciones; por un lado, incorpora a parejas sin distinción de sexo; pero descuida la regulación del régimen patrimonial, y les extiende ampliamente la aplicación de reglas conyugales, a la vez, pretende otorgar reconocimiento a las parejas del mismo sexo, pero sin siquiera conferirles un estado civil ${ }^{77}$. Debemos destacar que

\footnotetext{
${ }^{74}$ César Belluscio (2009), p. 805.

75 En este proceso tuvo una gran trascendencia la resolución № 28/1994 del Parlamento Europeo, que impulsó decididamente el reconocimiento institucional de la convivencia afectiva homosexual. Dicha resolución tuvo una notable repercusión en los países de la Unión Europea, marcando un punto de inflexión en el tratamiento del problema y propiciando el surgimiento de iniciativas legislativas dirigidas a conceder un estatuto jurídico a las uniones homosexuales.
}

76 Talavera Fernández (2001), pp. 77 y ss. Cita dentro de este grupo a las leyes de Unión de Hecho portuguesas del año 2001, la ley húngara de uniones estables no casadas de 1996 y el Pacto Civil de Solidaridad francés, aprobado en 1999; también encuadra el autor en esta categoría la mayoría de las leyes autonómicas de parejas aprobadas hasta ahora en España, a excepción de las leyes navarra y vasca.

77 Bascuñán Rodríguez (2012), p. 4. 
durante la tramitación del proyecto se ha producido un acercamiento relativo al modelo nórdico, sin alcanzar un asimilamiento a la institución matrimonial, pero la propuesta inicial ha sido matizada ${ }^{78}$.

Podemos resaltar el sentido igualitario presente en el proyecto, ya que por primera vez podrán acceder a él todas las parejas sin distinción de sexo, con ello se da una respuesta a la ausencia de regímenes que permitan a las parejas del mismo sexo tener derechos claramente establecidos. Esta orientación ha sido plasmada hoy en día como un requerimiento dentro de la esfera de los Derechos Humanos, como hemos señalado ${ }^{79}$.

Finalmente, el proyecto realiza reiteradas referencias a la intención de contribuir a otorgar certeza jurídica a las convivencias no matrimoniales, sobre esta materia señala: "La necesidad de regular y proteger estas uniones de hecho de manera de dar mayor certeza jurídica a los derechos y obligaciones que de ellas emanan"; luego reitera estos fundamentos señalando: "Nos asiste la convicción de que el Estado no está cumpliendo adecuadamente con su finalidad ni sus deberes primordiales si no ofrece un marco jurídico que, al menos, reconozca, respete y otorgue certeza jurídica".

Tal como hemos indicado, la respuesta actual que nos ofrece el Derecho se encuentra distante de reconocer en la convivencia la capacidad de producir efectos jurídicos directamente, esto contribuye a generar un estado de inseguridad jurídica, frente a los diversos conflictos que surgen en las relaciones de parejas. Sobre este punto, una posición minoritaria ha señalado que no existiría una verdadera necesidad de crear un estatuto particular, ya que tal incertidumbre no sería real, esto a propósito de la función que cumple la jurisprudencia al otorgar una serie de soluciones ${ }^{80}$.

\footnotetext{
${ }^{78}$ Prueba de ello se puede observar durante su tramitación en la Comisión de Legislación, Justicia y Reglamento, en ella se aprobó por mayoría de votos la indicación de otorgar el estado civil de convivientes legales a los pactantes. De esta manera, se incorporó al inciso tercero del artículo $1^{\circ}$ del proyecto de ley refundido. En Primer Informe de la Comisión de Constitución, Legislación y Justicia, Senado de Chile, 11/12/2013. Disponible en: http://www.senado.cl/appsenado/templates/tramitacion/ index.php\# [visitado el 28/05/2014].

${ }^{79}$ En el ámbito europeo resultó relevante la resolución del Parlamento Europeo № 28/1994 sobre "Igualdad de los Derechos de los homosexuales y Lesbianas en la Comunidad Europeo", aprobada el 8 de febrero de 1994. Esta orientó a los Estados a que se ponga fin "a la prohibición de contraer matrimonio o de acceder a regímenes jurídicos equivalentes a las parejas de lesbianas o de homosexuales"; garantizando a dichas uniones "los plenos derechos y beneficios del matrimonio"; en el mismo sentido la resoluciones dictadas sobre el respeto a los Derechos Humanos en la Unión Europea del 16 de marzo del año 1998. También la resolución del 15 de enero del año 2003, sobre matrimonio homosexual.

80 Domínguez Hidalgo (2012), p. 3.
} 
No compartimos dicho planteamiento, dado que un estatuto específico otorgará una buena respuesta a la inestabilidad jurídica que la omisión legislativa representa. Una manifestación de esta incertidumbre se expresa, a modo de ejemplo, en la posición sistemática de nuestros tribunales, quienes sostienen como criterio rector que la comunidad jurídica entre convivientes no surge por la sola convivencia -aun cumpliendo con todos los requisitos necesarios para su reconocimiento-, sino que se requiere acreditar el aporte común por parte de los convivientes, esto como consecuencia de la aplicación de las reglas del Derecho Patrimonial, promoviendo una clara injusticia, complejizando el camino para el conviviente más débil a la fecha de ruptura ${ }^{81}$.

A lo anterior debemos agregar la respuesta vacilante que nos ha entregado la jurisprudencia respecto de los elementos constitutivos de estas uniones para reconocerles efectos jurídicos, si bien con el tiempo se han ido uniformando relativamente los criterios, aún quedan temas pendientes, sólo a modo de ejemplo: a) los plazos de convivencia que se requieran para que esta produzca efecto; b) en la trascendencia que ocupa la descendencia en la convivencia; c) la diferencia de sexo como requisitos para reconocer efectos jurídicos, criterio inequívoco aplicado por nuestros tribunales, con la salvedad indicada anteriormente en materia de violencia intrafamiliar; d) procedencia de la compensación económica u otro tipo de indemnización ${ }^{82}$.

Desde el punto visto de vista valórico, el proyecto de ley de "Acuerdo de Vida en Pareja", si bien surge inicialmente como un modelo contradictorio entre el discurso y el modelo propuesto, durante su tramitación se ha enriquecido, configurándose como una proposición que permitirá al Estado fortalecer el sistema democrático, bajo una mirada pluralista del concepto de la familia jurídica, permitiendo armonizar el actual Derecho de Familia a las bases de la institucionalidad consagradas en la propia Constitución; permitiendo con ello garantizar una protección efectiva de los modelos familiares alternativos al modelo clásico radicado en la figura matrimonial, poniendo al día una de las áreas normativas de mayor injerencia en la subsistencia y desarrollo de la nación.

\footnotetext{
${ }^{81}$ En este sentido, Delgado con D'apollonio (2010): Corte Suprema, 19 de octubre de 2010, rol No 866/2009, (Recurso de Casación de forma y de fondo), en: Tratado de Jurisprudencia y Doctrina, Derecho de Familia, Tomo IV, Directora Paulina Veloso Valenzuela, Thomson Reuters, pp. 775-792. En el mismo sentido: Corte Suprema, de fecha 26/09/2007, publicada en Gaceta Jurídica 327, año 2007. Sin embargo, resulta interesante el voto en contra en la causa analizada recientemente ante la Corte Suprema (rol No 5367-2012) cuya sentencia se pronunció el 24 de junio del 2013.

${ }^{82}$ A modo de ejemplo: Bejarano y otros con Araya (1997): Corte de Apelaciones de Valparaíso, de 15 de septiembre de 1997; Díaz Vargas con Carvajal (1904): Corte Suprema, de 16 de febrero de 1904. Ver sentencias en: Donoso y Rioseco (2007), p. 20 y ss.
} 


\section{A modo de conclusión}

1. En el Derecho occidental moderno existe una amplia diversidad de respuestas frente a la realidad social de las uniones de hecho, éstas transitan inevitablemente bajo la presencia del régimen matrimonial, reflejadas básicamente en dos corrientes, por un lado la mantención de la institución matrimonial en un sitial de privilegio y, en un camino distinto, el planteamiento de equiparación entre todos los sistemas en un pleno trato igualitario.

2. En esta línea se formula una concepción pluralista del estatuto regulador de la familia, en que las parejas se enfrentan a diversas opciones que junto al matrimonio permiten adecuar el orden jurídico a la libre determinación de cada individuo, esto se conforma como un mandato consagrado en la Carta Fundamental, que coloca al Estado en una posición de carácter instrumental frente a cada individuo, debiendo generar las condiciones para que su proyecto de vida afectiva encuentre las vías de desarrollo adecuadas, dentro del contexto del ordenamiento jurídico.

3. El sustrato jurídico tiene su base en que no es posible generar sistemas de mayor o menor reconocimiento, bajo la noción de funcionalidad que represente cada grupo para los fines del propio Estado, por cuanto, de considerarse así, se invierte el sentido que representa el orden público como orientador de los actos públicos; en esto, lo esencial es la constitución de familia como una cuestión estructural para la consideración de la persona y sus derechos, asociados a conceptos como dignidad, igualdad, todo ello garantizado bajo la noción de Derechos Humanos, cuestión vital para la subsistencia de un país organizado democráticamente.

4. En este escenario, el proyecto de ley de Acuerdo de Vida en Pareja viene a saldar una deuda pendiente del ordenamiento jurídico nacional entrado el siglo XXI.

La dicotomía inicial entre el discurso valórico expresado en su preámbulo y la técnica legislativa con que se plasmó su contenido (al reconocer a la familia en las uniones de hecho y, al mismo tiempo, ofrecer soluciones residuales en materias trascendentales como el régimen patrimonial, o en el reconocimiento de efectos personales) ha sido salvada, durante su tramitación en sede parlamentaria, dando luces de que el resultado responderá a los cánones de respeto e igualdad establecidos en las normas internacionales.

5. Sobre la base de este criterio, quizás el mayor valor que representa el proyecto de ley es que viene a clarificar definitivamente la pluriformidad familiar reconocida en el ordenamiento jurídico nacional, asimismo el Derecho de Familia se hace cargo de esta múltiple realidad, dándole cauce. Sólo queda pendiente definir la posición neutral que el legislador debe tener en la valorización de las diferentes formas de vida que adopten los individuos, cuestión que se reflejará en el estatuto definitivo que arroje su tramitación en el Congreso. 


\section{BiBLIOGRAFÍA CITADA}

Barrientos Grandon, Javier (2008): De las uniones de hecho: Legislación, doctrina y jurisprudencia (Santiago, Editorial LexisNexis).

Barrientos Grandon, Javier (2006): "Sobre La Noción de 'Conviviente' utilizada en el artículo 390 del Código Penal", en: Revista Chilena de Derecho Privado (No 7), pp. 191-233.

Barrientos Grandon, Javier y Novales Alquézar, Aránzazu (2004): Nuevo Derecho Matrimonial Chileno (Santiago, Editorial LexisNexis).

Barrientos Grandon, Javier (2011): Derecho de las Personas, El Derecho Matrimonial (Santiago, Editorial LegalPublishing).

Bascuñán Rodríguez, Alejandro (2012): “¿El acuerdo de Vida en Pareja: Un Bien Instrumental o Simbólico?", en: La Semana Jurídica ( Nº $\left.^{\circ}\right)$, p. 4.

Biedma Ferrer, José (2011): "Uniones de hecho y principio de igualdad. Algunas cuestiones conflictivas", en: Anuario Facultad de Derecho, Universidad de Alcalá IV, pp. 199-222.

BINSTOCK, Georgina (2009): Tendencias sobre la convivencia, matrimonio y maternidad en áreas urbanas de Argentina (Centro de Estudios de Población (CENEP)-CONICET). Disponible en: http://www.alapop. org/2009/Revista/ Articulos/RELAP6-art06.pdf [visitado 28/05/2014].

Bossert, Gustavo y Zanoni, Eduardo (2004): Manual de Derecho de Familia, sexta edición (Buenos Aires, Editorial Astrea).

Cantero Núñez, Federico (2001): "Uniones de Hecho", en: J. F. Delgado De Miguel coordinador general, Instituciones de Derecho Privado (Madrid, Ed. Consejo General del Notariado y Civitas S.A.), tomo IV, Familia, volumen I, pp. 269-488.

César Belluscio, Augusto (2009): Evolución del Pacto Civil de Solidaridad Francés, Revista La Ley, Tomo 2009 B, p. 805.

Corral TalCiani, Hernán (1994): Familia y Derecho (Santiago, Colección Jurídica Universidad de Los Andes).

Corral Talciani, Hernán (2012): "El acuerdo de Vida en Pareja: De la Unión Civil al Matrimonio Homosexual", en: La Semana Jurídica (Año I, No 0), pp. 9-11.

Cornejo Chávez, Héctor (1999): Derecho Familiar Peruano. Sociedad Conyugal. Sociedad Paterna Filial. Amparo Familiar del Incapaz (Lima, Ediciones Lima, Gaceta Jurídica Editores S.R.L.).

Dé PICó RuBıO, Jorge (2011): “Evolución y actualidad de la concepción de familia. Una apreciación de la incidencia positiva de las tendencias dominantes a partir de la Reforma del Derecho Matrimonial chileno", en: Revista lus et Praxis (Año 17, № 1), pp. 31-56. 
De Verda y Beamonte, José (2003): “Efectos Económicos en las Uniones de Hecho en la Jurisprudencia Española", en: Revista Chilena de Derecho Privado (No 1), pp. 149-180.

Díez-Picazo, Luis y Gullón Ballesteros, Antonio (2012): Sistema de Derecho Civil, undécima edición (Madrid, Editorial Tecnos), volumen IV, tomo I, Derecho de Familia.

Domínguez Hidalgo, Carmen (2012): El Acuerdo de Vida en Pareja y sus Fundamentos: Necesidad de un Debate Serio, en: La Semana Jurídica (año I, $\left.\mathrm{N}^{\circ} 0\right)$, p. 3.

Donoso, Florencia y RıOseco, Andrés (2007): El concubinato ante la jurisprudencia chilena (Santiago, Editorial LexisNexis).

Figueroa Yáñez, Gonzalo (2005): "El Pacto de Convivencia: Una alternativa al Pacto de Matrimonio", en: Estudios de Derecho Civil, Jornadas Nacionales de Derecho Civil (Santiago, Editorial LegalPublishing), pp. 423-446.

Figueroa Yáñez, Gonzalo (1995): Persona, Pareja y Familia (Santiago, Editorial Jurídica de Chile).

García Cantero, Gabriel (2004): “¿Derecho a no Casarse?", en: Actualidad Civil ( $N^{\circ}$ 1, Sección A Fondo, Editorial La Ley), tomo 1, p. 3.

García Cantero, Gabriel (2010): "Vértigo ante el Abismo", en: Revista Chilena de Derecho de Familia ( ${ }^{\circ}$ 1), pp. 11-14.

García Cantero, Gabriel (1982): "Familia y Constitución", en: El desarrollo de la Constitución española de 1978, La Ley (2500/1978) (Zaragoza, Libros Pórtico Zaragoza), pp. 193-213.

García-Hervás, Dolores (2001): "Panorámica Legislativa sobre Uniones de Hecho", en: Revista lus Canonicum (XLI, No 81), pp. 319-346.

García Rubio, María Paz (2006): "Las uniones de hecho en España. Una visión jurídica", en: Anuario de la Facultad de Derecho de la Universidad Autónoma de Madrid, ( ${ }^{\circ}$ 10), pp. 113-138.

Gavidia SÁnchez, Julio (2004): "La unión libre: familia, no matrimonio", en: Diario La Ley (№ 6038, Sección Doctrina, 11 Jun., Año XXV, Ref. D-131), pp. 1-24.

GrimaldI, Michel (2004): "El pacto civil de solidaridad en el derecho francés", en: Revista Chilena de Derecho Privado UDP (No 3), pp. 69-82.

Guzmán Brito, Alejandro (2001): El Derecho Privado Constitucional de Chile (Valparaíso, Ediciones Universitarias).

Hernández Paulsen, Gabriel (2007): "Uniones afectivo-sexuales y matrimonios entre personas del mismo sexo en el Estado democrático de derecho", en: Estudios de Derecho Civil III, Jornadas Nacionales de Derecho Civil (Valparaíso, Editorial LexisNexis), pp. 1-918. 
Lacruz Berdejo, José Luis et al. (2005): Elementos de Derecho Civil, IV Familia, segunda edición, revisada y puesta al día por Joaquín Rams Albesa (Madrid, Editorial Dykinson).

LATHROP Gómez, Fabiola (2009): Informe de la Comisión de Familia sobre proyectos de ley que establecen regulación para las uniones de hecho, Intervención audiencia pública en el Congreso Boletines $\mathrm{N}^{\circ}$ s. 4153-18-4187-18, 26 de junio de 2009.

Martin CASAls, Miquel (2013): "El derecho a la "convivencia anómica en pareja": ¿Un nuevo derecho fundamental?", en: InDret (3/2013).

Martínez De Aguirre Aldaz, Carlos et al. (2011): Curso de Derecho Civil, tercera edición (Madrid, Editorial Constitución y Leyes S.A. -Colex-), volumen IV, Derecho de Familia.

Martínez De Aguirre Aldaz, Carlos (2007): "Nuevos Modelos de Familia: La Respuesta Legal", en: Revista Española de Derecho Canónico (Volumen LXIV, No 163), pp. 703-744).

Martínez De Aguirre Aldaz, Carlos (2000): "Acuerdos entre Convivientes More Uxorio", en: Anales de la Academia Matritense del Notariado, 17 de febrero del 2000, pp. 5-49.

Mesa Marrero, Carolina (2006): Las Uniones de Hecho: Análisis de la Relaciones Económicas y Sus Efectos, tercera edición (Navarra, Editorial Thompson Aranzadi).

Meza Barros, Ramón (1975): Manual de Derecho de Familia (Santiago, Editorial Jurídica de Chile), tomo I.

Pantaleón Prieto, F. (1998): "Régimen jurídico civil de las uniones de hecho", en: Uniones de Hecho (eds. Martinell, J. M. y Areces Piñol, M. T., Lleida, Departament de Dret Privat, Facultat de Dret i Economía, Universitat de Lleida), pp. 71-72.

Parra Martín, María Dolores (2005): "Mujer y Concubinato en la Sociedad Romana", en: Anales de Derecho, Universidad de Murcia (№ 23), pp. 239-248.

Peña González, Carlos (1996): “¿Hay Razones Constitucionales Fuertes a favor de un Estatuto Igualitario?", en: Instituciones Modernas de Derecho Civil (Santiago, Editorial Conosur), pp. 140-150.

Ramos Pazos, René (2006): Derecho de Familia, séptima edición actualizada (Santiago, Editorial Jurídica de Chile), tomo II.

RocA Trias, Encarna (2006): "Familia y Constitución", en: Anuario de la Facultad de Derecho de la Universidad Autónoma de Madrid (№ 10), pp. 207-228.

RodríGuez, Jorge (2004): "Tendencias recientes de las uniones consensuales en América Latina", en: Cambio de las familias en el marco de las transformaciones globales, necesidad de políticas públicas eficaces (Santiago, Cepal, Serie Seminarios y Conferencias), pp. 77-96. 
Sánchez Martínez, Olga María (2000): "Constitución y parejas de hecho. El matrimonio y la pluralidad de estructuras familiares", en: Revista Española de Derecho Constitucional ( No 58, Año 20), pp. 45-69.

Tapia Rodríguez, Mauricio (2007): "Constitucionalización del derecho de familia(s) el caso chileno: Las retóricas declaraciones constitucionales frente a la lenta evolución social", en: Revista Chilena de Derecho Privado ( $\mathrm{N}^{\circ}$ 8), pp. 155-202.

Talavera Fernández, Pedro (2007): "El derecho europeo ante el matrimonio y las uniones de hecho de personas del mismo sexo", en: Ius, Revista del Instituto de Ciencias Jurídicas de Puebla ( No 20), pp. 6-25.

Talavera Fernández, Pedro (2001): La unión de hecho y el derecho a no casarse (Granada, Editorial Comares).

Turner Saelzer, Susan (2007): "Uniones de hecho y su regulación legal", en: A. Guzmán Brito, Estudios de Derecho Civil (Santiago, LexisNexis), pp. 167176.

Turner Saelzer, Susan (2010): "La Unión de Hecho como Institución del Derecho de Familia y su Régimen de Efectos Personales", en: Revista lus et Praxis (Año 16, № 1), pp. 85-98.

Varas Braun, Juan (2010): "Uniones de Hecho y Derecho Sucesorio", en: Revista de Derecho (Valdivia), (Volumen XXIII, No 2), pp. 9-22.

\section{NORMAS JURÍDICAS CITADAS}

Código Civil chileno, 30 de mayo del año 2000.

Código Penal chileno, 12 de noviembre de 1874.

Código de Familia de Bolivia, 23 de agosto de 1972.

Código Procesal Penal chileno, 12 de octubre de 2000.

Ley N 14.908 sobre Abandono de Hogar y Pago de Pensiones Alimenticias. Diario Oficial, 5 de octubre de 1962.

Ley 232 sobre Hogar común de cohabitantes extramatrimoniales de Suecia de 1 de enero 1988.

Ley No 99/944 de Pacto de Solidaridad de Francia 15 de noviembre de 1999.

Ley $\mathrm{N}^{\circ} 1004$ de la legislatura federal de la ciudad autónoma de Buenos Aires de 2002.

Ley N 18.246 sobre Unión Concubinaria de Uruguay, 10 de enero de 2008.

Ley $\mathrm{N}^{\circ} 54$ de Colombia, 31 de diciembre de 1990.

Ley francesa 728 reformatoria del Código Civil del año 2006.

Ley de Matrimonio Civil chilena. Diario Oficial, 16 de enero de 1884.

Ley № 19.947 de Matrimonio Civil chilena de 2004. Diario Oficial, 17 de mayo de 2004. 
Ley No 19.968 sobre Tribunales de Familia. Diario Oficial, 30 de agosto de 2004. Ley $N^{\circ} 20.066$ violencia intrafamiliar. Diario Oficial, 7 de octubre de 2005.

Ley Nacional $N^{\circ} 26.618$, sobre Matrimonio entre personas del mismo sexo de Argentina, 15 de julio del 2010.

Ley mexicana de alianza entre personas del mismo sexo, 29 de diciembre de 2009.

Ley de Matrimonio Igualitario de Uruguay, Diario Oficial 9 de mayo de 2013.

\section{JURISPRUDENCIA CITADA}

Sánchez Ponce, Rosa con Sucesión Parada Merino (2012): Corte Suprema de Chile, 7 de marzo de 2012 (Recurso de Casación de forma y de fondo), rol No 337-2011.

(2007): Corte de Apelaciones de La Serena, enero de 2007 (Recurso de Nulidad), rol No 373-2006.

Bejarano y otros con Araya (1997): Corte de Apelaciones de Valparaíso, 15 de septiembre de 1997, en: Gaceta Jurídica 206, p. 90.

Hidalgo Osorio María con Misa Toro Gilda (1987): Corte de Apelaciones de Valparaíso, 23 de junio de 1987, en: Gaceta Jurídica 85, p. 50.

(2013): Corte de Apelaciones de Santiago, 15 de marzo de 2013, rol № 38-2013. Delgado con D'apollonio (2010): Corte Suprema, 19 de octubre de 2010, rol No 866/2009, (Recurso de Casación de forma y de fondo), en: Tratado de Jurisprudencia y Doctrina, Derecho de Familia, Tomo IV, Directora Paulina Veloso Valenzuela, Thomson Reuters, pp. 775-792.

Díaz Osorio con Troncoso Mouriño (2007): Corte Suprema, 26 de septiembre de 2007, (Recurso de Casación de forma y de fondo), en: Gaceta Jurídica 327. Candia Ferrada con María Valenzuela y otros (2013): Corte Suprema, 24 de junio del 2013, (Recurso de Casación en el fondo), rol № 5367-2012.

Requerimiento de inconstitucionalidad deducido por Carlos Ominami Pascual respecto de los artículos 2331 del Código Civil y 40, inciso segundo, de la ley $\mathrm{N}^{\circ} 19.733$, sobre libertades de opinión e información y ejercicio del periodismo, rol № 1185 (2008): Tribunal Constitucional de Chile, 16 de abril de 2009.

Requerimiento de inconstitucionalidad deducido en contra de algunas disposiciones de las "Normas Nacionales sobre Regulación de la Fertilidad", aprobadas por el decreto supremo № 48 de 2007 del Ministerio de Salud, (2008): Tribunal Constitucional de Chile, rol № 740/ 2007, 18 de abril de 2008, considerandos 46 y 47. 